\title{
Soil tillage and sugarcane planting: an assessment of cost and economic viability
}

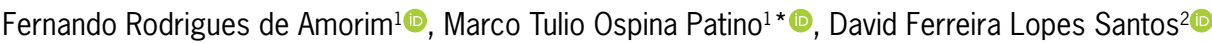

'Universidade Estadual de Campinas/FEAGRI, Av. Cândido

Rondon, 501 - Cidade Universitária - 13083-875 -

Campinas, SP - Brasil.

¿Universidade Estadual de São Paulo "Júlio de Mesquita

Filho" - Depto. de Economia, Administração e Educação, Via

de Acesso Prof. Paulo Donato Castellane, s/n - 14884-900

- Jaboticabal, SP - Brasil.

*Corresponding author <mtospina@unicamp.br>

Edited by: Thiago Libório Romanelli

Received November 27, 2019

Accepted October 09, 2020
ABSTRACT: Yield and profitability levels in sugarcane crops demonstrate the importance of the agricultural practices adopted, especially for soil preparation and planting systems. This study evaluated the costs involved in 40 alternative methods for the establishment of sugarcane crops resulting from the combination of eight soil preparation systems and five planting options, followed by an assessment of the economic viability of sugarcane production for suppliers and sugar mills. Data were collected from 31 sugar mills and 42 suppliers in São Paulo State, Brazil, from the 2016/17 season. The cost analysis and discounted cash flow analysis were used to calculate economic viability. Localized soil preparation with a fixed application rate of inputs (soil amendments) and mechanized planting with a variable application rate of fertilizers were the least costly systems to establish the sugarcane crop. Regarding the sugarcane establishment system, the medium-sized sugar mills were the most economically viable when compared to independent sugarcane producers. There was no significant difference in cost to establish sugarcane crops across the various sized groups of suppliers and we identified that costs rose as the size of the sugar mills increased.

Keywords: Saccharum spp, mechanization, variable rate, yield, profitability

\section{Introduction}

Brazil is the world's largest sugarcane producer, with three main products (sugar, biofuel, and bioenergy) ranking the country as a major global player in these sectors (Cardoso et al., 2019). Nevertheless, the sugarcane ethanol industry in Brazil has faced a challenge to achieve high yields to make cane crops profitable, adequately remunerating rural producers and sugar mills (Farina et al., 2018).

The economic results from the sector reveal that profitability is lower than the capital cost, as well as increased indebtedness of farmers and mills, reduced investment capacity, and reduced cultivated areas (Manoel et al., 2018). The sugarcane crop cycle lasts between four and six years; therefore, decisions regarding investment and production systems are highly relevant (Farinelli et al., 2018).

Soil preparation and planting activities are the most problematic, with a direct and significant influence on economic performance (Moraes et al., 2016). Consequently, heterogeneity of results between sugar mills and independent suppliers is directly linked to these practices. Differences in performance are also associated to the different production scales at these units (Santos et al., 2018).

Previous empirical studies on the representativeness of sugarcane soil preparation and planting systems were based on limited samples or experiments and specific management systems (Carvalho et al., 2011). The economic viability and inherent risks associated to the main agricultural practices in the crop establishment and development is a research frontier where results can contribute to the literature and, primarily, to the sector itself, which encompasses more than 300 sugar mills and 18,000 rural producers in Brazil (Farina et al., 2018; Santos et al., 2018).
Therefore, the aim of this study was to analyze and compare the production costs and cane yields from the combination of four soil preparation systems (conventional, no-till, low-till, and localized). Each system had two application options of soil amendments ${ }^{1}$ (applied at fixed or variable application rates), comprising eight soil preparation systems with three planting options (semi-mechanized, mechanized, presprouted sets) and two options for fertilizer ${ }^{2}$ application at fixed or variable application rates. Thus, five planting systems were compared because the planting system of pre-sprouted sets only uses a fixed application rate of fertilizer application. The combination of these eight soil preparation systems and five planting options determined the 40 systems analyzed. In addition, we compared the production costs at three production scales of sugar mills and assessed the economic viability of small-scale sugarcane suppliers and medium-scale sugarcane mills.

\section{Materials and Methods}

In the studied region (Ribeirão Preto: $21^{\circ} 10^{\prime} 36^{\prime \prime}$ S, $47^{\circ} 49^{\prime} 15^{\prime \prime} \mathrm{W}$, altitude of $531 \mathrm{~m}$ ), two important associations CANAOESTE and SOCICANA with 250

\footnotetext{
Within the soil amendment procedure for sugarcane production, the addition of limestone to correct soil acidity must be based on chemical analysis of representative samples of the soil in question. The addition of gypsum does not correct acidity, but it is a great source of calcium and sulfur and it is used together with lime in planting (Moraes, et al., 2016).

${ }^{2}$ Soil fertilization for sugarcane production requires the supply of the main elements - nitrogen, phosphorous and potassium - according to preliminary soil analysis and expected productivity (Santos, et al., 2018).
} 
sugarcane producer members provided the contacts of possible respondents. For both mills and suppliers, the questionnaire was tested by initial application in five mills randomly selected.

The sugar mill sample consisted of data from 31 mills and was established using a probabilistic approach for a finite sample and confidence interval (CI) $<10 \%$. Given that 157 sugar mills were active in São Paulo State in 2016, this required a sample size of 27 mills to give statistically significant results; therefore, the sample chosen was more than adequate, as there are only 27 mills in Ribeirão Preto region.

Regarding the sample of suppliers, there were 18,078 sugarcane producers in the Center-Southern region of Brazil and circa 250 independent producers in the study region supplying individually between 12,000 and 100,000 tons of sugarcane to the mills; thus, the recommended sample size was 39 producers, and 42 were selected as respondents.

The research data were generated from answers to a questionnaire, filled out in person or via email between Feb and Jul 2017. The instrument contained 15 questions related to sugarcane soil preparation and planting systems and their associated costs and cash flow.

The suppliers and sugar mills were classified into three groups based on the area used for sugarcane farming. We identified six small-scale sugar mills that planted between 8,500 and 19,999 hectares, 20 medium-scale mills with a planted area of 20,000 to 39,999 hectares, and five large-scale mills with 40,000 to 70,000 hectares.

The group of suppliers consisted of 20 small, eight medium and 14 large-scale farmers, with planted areas of 112 to 399, 400 to 799, and over 800 hectares, respectively. The average costs of soil preparation and sugarcane planting from each group were used as indicators in the cost, risk, and economic viability analyses.

A crop cycle of five harvests was considered to calculate revenue, as indicated by Farinelli et al. (2018), and the average price per metric ton of sugarcane was determined based on total recoverable sugar (TRS) data from 2003 to 2016.

For the economic viability analysis, discounted cash flow (DCF) was calculated using the net present value (NPV) and internal rate of return (IRR) as indicators of viability (Farinelli et al., 2018; Santos et al., 2018). In line with the approach described by Rocha et al., (2018), the annual minimum acceptable rate of return on investment was set at $15 \%$, which was the average yield required in agricultural letters of credit (LC) in 2017 and was used as the discount rate in the DCF analysis.

Differences in soil preparation and planting strategies between the groups studied and their commercial conditions for inputs acquisition generate considerable volatility in the costs of the systems, influencing economic viability. To assess this situation, we performed an analysis using the same production value in the 10-year time horizon assessed, considering a mean annual yield in a crop cycle of five years. This yield was defined after analyzing random values from a distribution of yields using the mean and standard deviation to capture the variation in yields over the two crop cycles.

The sensitivity analysis was therefore performed by considering price variations in net revenue. Therefore, the net cash flow (NCF) per year was determined for the sensitivity analysis using three scenarios (optimistic, realistic, and pessimistic). The pessimistic scenario corresponds to a $10 \%$ decline in net revenue, while the optimistic scenario considers a $10 \%$ increase. This type of analysis was used by Neupane et al. (2017), Marin and Jones (2014).

\section{Results and Discussion}

\section{Methods and cost of soil preparation for suppliers and sugar mills}

The soil preparation methods reported by respondents are shown in Table 1 . There were eight different methods, two of which were exclusively used by mills,

Table 1 - Description of the soil preparation systems used by suppliers and sugar mills.

\footnotetext{
Soil preparation system

PRCONVFR Conventional land preparation [harrows: rotary, intermediate and leveling, subsoiler or plow, mechanical stubble remover] with a fixed rate of soil amendments.

PRCONVVR Conventional land preparation [harrows: rotary, intermediate and leveling, subsoiler or plow, mechanical stubble remover] with a variable rate of soil amendments.

PRLOCAFR * * Localized cultivation [Subsoiler, rotary harrow and wheel rake] with a fixed rate of soil amendments.

PRLOCAVR* Localized cultivation [Subsoiler, rotary harrow and wheel rake] with a variable rate of soil amendments.

PRLOWFR* * Low-till [subsoiling and intermediate harrow or plow] with a fixed application rate of soil amendments.

PRLOWVR Low-till [subsoiling and intermediate harrow or plow] with a variable application rate of soil amendments.

PRNOTFR No-till [rotary cutter, or subsoiler with declodder] with a fixed application rate of soil amendments.

PRPNOTVR No-till [rotary cutter, or subsoiler with declodder] with a variable application rate of soil amendments.

* used only by sugar mills; * ${ }^{*}$ used only by suppliers. Source: Compiled by the authors; FR = Fixed rate: uniform application of soil amendments across the entire area with the average calculated via the soil analysis; VR = Variable rate: method for application of soil amendments according to each point analyzed by grid or management zone.
} 
and one only by suppliers. Among the sugarcane mills and suppliers studied, $52 \%$ and $79 \%$ respectively used only one soil preparation method. The planting methods studied are described in Table 2, with five systems used by sugarcane suppliers, three using a fixed application rate of fertilizers and two systems using a variable application rate, with four systems used by sugarcane mills, three with a fixed application rate of fertilizers and one with a variable application rate. It is important to note that there are fixed and variable application rates of some soil amendments (lime, gypsum etc.) applied as part of the land preparation while the fertilizer is applied at planting either by a fixed or variable rate.

Both suppliers and mills used a fixed and a variable application rate of inputs with conventional land preparation; however, suppliers used low-till and no-till land preparation methods, while some mills used localized tillage. The system with the lowest costs and standard deviation was the no-till fixed rate approach used by suppliers (Table 3).

In all instances when land preparation methods were compared, costs of suppliers were lower than those of the mills, in some cases by a large margin. The large management structure of sugar mills means that their labor costs are higher; however, this cannot be confirmed without analyzing related aspects of economies of scale.
The sugarcane mills also have higher mechanization costs for all the systems studied, since machinery replacement and depreciation is taken into account. In addition, suppliers used fewer inputs per hectare in order to reduce costs.

Demattê et al. (2014) analyzed the costs of soil amendments, fertilizers, and soil analysis between the fixed and variable application rate systems and found variations according to the size of the study site, meaning that when the site is smaller, the cost of soil analysis for the variable rate system is higher. According to Sanches et al. (2019), an advantage of the variable rate system is that it allows sugar mills and producers to select suitable varieties and apply inputs and fertilizers based on the needs of each plot, ensuring more sustainable and profitable production.

\section{Methods and cost of planting for suppliers and sugar mills}

The analysis of responses concerning the planting method (Table 4) showed that $21 \%$ of suppliers used two or three systems and $79 \%$ only one, while many of the sugarcane mills were using up to three planting systems and $52 \%$ used only one. Among those who used only one planting system, $93 \%$ of suppliers and

Table 2 - Description of the planting methods used by sugarcane suppliers and sugar mills.

Planting Methods

PLSEMECFR Semi-mechanized sugarcane planting using machinery (tractors, wheel loaders, implements and trucks), a number of different workers (machine operator, general services, drivers, field hand labor and farm business manager) with a fixed rate of fertilizer

PLSEMECVR $^{*}$ Semi-mechanized sugarcane planting using machinery (tractors, wheel loaders, implements and trucks), a number of different workers (machine operator, general services, drivers, field hand labor and farm business manager) with a variable rate of fertilizer

PLMECHANFR Mechanized sugarcane planting using only machines; seed pieces or sets are cut by sugarcane harvesters, transported to the planting site by transshipment trucks and/or tractors, and planting is performed using a tractor pulling a planter that carries out three operations simultaneously: furrow opening, distribution and covering. Fertilizer application with a fixed rate.

PLMECHANVR Mechanized sugarcane planting using only machines; seed pieces or sets are cut by sugarcane harvesters, transported to the planting site by transshipment trucks and/or tractors, and planting is performed using a tractor pulling a planter that carries out three operations simultaneously: furrow opening, distribution and covering. Fertilizer application with a variable rate.

PLPRESPRFR Pre-sprouted sugarcane sets planted with furrow opening, fixed rate fertilization and agrochemicals application before planting, performed by manual transplanting or by a mechanized transplanter.

* System used only by suppliers. Source: Compiled by the authors; FR = Fixed rate: uniform application of fertilizer across the entire area with the average calculated via the soil analysis. VR = Variable rate: method for application of fertilizer according to each point analyzed by grid or management zone.

Table 3 - Costs incurred in soil preparation systems used by sugarcane suppliers (SS) and mills (SM).

\begin{tabular}{|c|c|c|c|c|c|c|}
\hline \multirow[b]{2}{*}{ Soil preparation system } & \multirow{2}{*}{$\begin{array}{l}\text { Percentage of use } \\
\text { for each system }\end{array}$} & \multicolumn{4}{|c|}{ Costs (US\$ ha-1) } & \multirow{2}{*}{$\begin{array}{c}\text { Standard deviation } \\
\text { US\$ }\end{array}$} \\
\hline & & Mechanization & Labor & Inputs* & Total & \\
\hline PRCONVFR (SS) & 67 & 209 & 111 & 34 & 354 & 24 \\
\hline PRCONVFR (SM) & 46 & 329 & 108 & 57 & 494 & 35 \\
\hline PRCONVVR (SS) & 11 & 244 & 115 & 51 & 411 & 27 \\
\hline PRCONVVR (SM) & 32 & 324 & 75 & 111 & 509 & 35 \\
\hline PRLOWFR (SS) & 9 & 165 & 28 & 82 & 275 & 19 \\
\hline PRNOTFR (SS) & 10 & 154 & 28 & 84 & 266 & 18 \\
\hline PRLOCAFR (SM) & 7 & 257 & 39 & 116 & 411 & 28 \\
\hline
\end{tabular}

See Table 1 for the meaning of the acronyms. * Inputs: PRCONVFR (SS): (1.2 $\mathrm{t} \mathrm{ha}^{-1}$ of limestone); PRCONVFR (SM): (1.6 $\mathrm{t} \mathrm{ha}^{-1}$ of limestone $+0.5 \mathrm{t} \mathrm{ha} \mathrm{a}^{-1}$ of gypsum); PRCONVVR (SS): (1.4 tha-1 of limestone + $0.5 \mathrm{tha}^{-1}$ of gypsum); PRCONVVR (SM): (0.6 tha-1 of limestone $+0.4 \mathrm{tha}^{-1}$ of phosphate); PRLOWFR(SS): (4 liters per ha of herbicide + 1.6 tha-1 limestone + $1.0 \mathrm{t} \mathrm{ha}^{-1}$ of gypsum); PRNOTFR (SS): ( 3 liters per ha of herbicide $+1.7 \mathrm{t} \mathrm{ha}^{-1}$ of limestone $+1.1 \mathrm{tha}^{-1}$ of gypsum); PRLOCAVR (SM): ( 3 liters per ha of herbicide $+1.5 \mathrm{tha}^{-1}$ of limestone $+0.7 \mathrm{tha}^{-1}$ of gypsum $+0.2 \mathrm{tha}^{-1}$ of phosphate). Source: Data compiled from the survey applied by the authors. 
$74 \%$ of mills used a fixed application rate of fertilizers with $7 \%$ of suppliers and $26 \%$ of mills using a variable application rate.

The most widely used planting methods were semi-mechanized planting with a fixed application rate of fertilizers among suppliers and mechanized planting with a fixed application rate of fertilizers by sugar mills. Moreover, results also showed the use of mechanized planting with a fixed application rate of fertilizers by suppliers as well as semi mechanized planting with a fixed application rate of fertilizers and mechanized planting with a variable application rate of fertilizers by mills. The least costly systems were mechanized planting with a fixed application rate of fertilizers for suppliers (US\$ 1,330 $\mathrm{ha}^{-1}$ ) and mechanized planting with a variable application rate of fertilizers for sugarcane mills (US\$ 1,327 $\mathrm{ha}^{-1}$ ) (Table 4); nevertheless, mechanized planting represented $25 \%$ of the planted area, while mechanized planting accounted for only $22 \%$. Costs ranged from US $\$ 1,330$ to $1,378 \mathrm{ha}^{-1}$ for suppliers and from US\$ 1,327 to $1,392 \mathrm{ha}^{-1}$ for mills. Considering all the planting methods assessed, mechanized planting was the least costly with a variable application rate of inputs used by suppliers. However, there was no significant difference in costs between the various planting methods.

Mechanical planting showed the lowest total cost per hectare because it required less labor and fewer inputs than the other planting systems did. The new planting system of pre-sprouted sets of sugarcane reported the highest yield $\left(95 \mathrm{tha}^{-1}\right)$ among all the planting systems analyzed. Regrettably, the survey did not provide enough detailed information about this system to establish comparisons with the other systems.

Another way of analyzing the data gathered at the interviews is by aggregating preparation and planting practices to identify the three least costly systems for suppliers and mills. The lowest cost system among suppliers using no-till soil preparation with a fixed application rate of inputs and mechanized planting with a fixed application rate of fertilizers. The mills achieved the lowest cost using the localized system with a variable application rate of inputs for soil preparation and mechanized planting with a variable application rate of fertilizers for planting (Figure 1). The overall analysis of the recorded data indicated that the cost was higher when the variable rate system for inputs was used for soil preparation and planting were considered together, and both used the variable rate system for inputs. Suppliers reported lower costs with the use of a fixed application rate of inputs in both practices and the mills achieved the same condition using a fixed application rate of inputs for soil preparation and a variable application rate of fertilizers at planting.

However, the highest yields (data not shown) were associated with the conventional soil preparation system and the mechanized planting system, all of which used a variable application rate of inputs for soil amendments and the other inputs applied at planting. Nevertheless, it is not possible to generalize from these results because

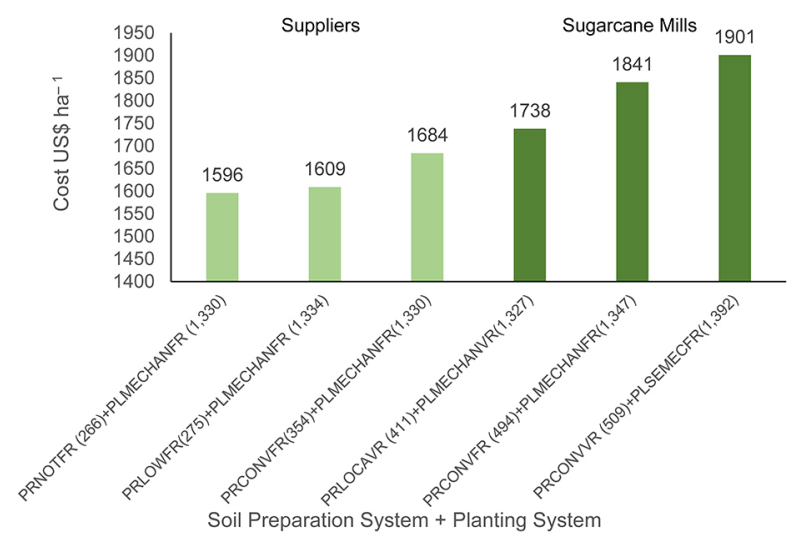

Figure 1 - Cost of soil preparation plus sugarcane planting systems used by suppliers (SS) and sugar mills (SM) in US\$ ha-1. ${ }^{*}$ See Tables 1 and 2 for the meaning of the acronyms. Source: Data compiled from the survey applied by the authors.

Table 4 - Costs incurred in planting systems used by sugarcane suppliers (SS) and mills (SM).

\begin{tabular}{|c|c|c|c|c|c|c|}
\hline \multirow{2}{*}{ Planting system } & \multirow{2}{*}{$\begin{array}{l}\text { Percentage of use for } \\
\text { each system }\end{array}$} & \multicolumn{4}{|c|}{ Costs (US\$ ha-1) } & \multirow{2}{*}{$\begin{array}{c}\text { Standard deviation } \\
\text { US\$ }\end{array}$} \\
\hline & & Mechanization & Labor & Inputs* & Total & \\
\hline PLSEMECFR(SS) & 60 & 367 & 114 & 854 & 1334 & 94 \\
\hline PLSEMECFR(SM) & 23 & 415 & 116 & 861 & 1392 & 96 \\
\hline PLMECHANFR(SS) & 25 & 397 & 82 & 851 & 1330 & 94 \\
\hline PLMECHANFR(SM) & 52 & 407 & 97 & 843 & 1347 & 94 \\
\hline PLMECHANVR(SM) & 22 & 398 & 119 & 810 & 1327 & 91 \\
\hline PLPRESPRFR(SS) & 8 & 353 & 122 & 903 & 1378 & 98 \\
\hline
\end{tabular}

See Table 2 for the meaning of the acronyms. ${ }^{*}$ Inputs: PLSEMECFR(SS): $\left(0.7 \mathrm{t} \mathrm{ha}^{-1}\right.$ of fertilizer +300 grams of insecticide +500 grams of fungicide $+15 \mathrm{t}$ ha $^{-1}$ of sugarcane seedling +250 grams of herbicide + other inputs: $\mathrm{nsm}=$ nematicide, stimulant and micronutrients); PLSEMECFR(SM): $\left(0.3 \mathrm{t} \mathrm{ha}{ }^{-1}\right.$ of fertilizer +300 grams of insecticide +500 grams of fungicide $+17 \mathrm{t} \mathrm{ha}^{-1}$ of sugarcane seedlings +250 grams of herbicide + other inputs (nsm); PLMECHANFR(SS): ( $0.7 \mathrm{t} \mathrm{ha}^{-1}$ of fertilizer +300 grams of insecticide +500 grams of fungicide $+15 \mathrm{tha}^{-1}$ of sugarcane seedlings +250 grams of herbicide + other inputs: $\mathrm{nsm}$ ); PLMECHANFR(SM): $\left(0.5 \mathrm{t} \mathrm{ha}^{-1}\right.$ of fertilizer +300 grams of insecticide +500 grams of fungicide $+16 \mathrm{t} \mathrm{ha}^{-1}$ of sugarcane seedlings +250 grams of herbicide + other inputs: nsm); PLMECHANVR(SM): (0.4 tha-1 of fertilizer +300 grams of insecticide +500 grams of fungicide $+13 \mathrm{tha}^{-1}$ of sugarcane seedlings +250 grams of herbicide + other inputs: nsm); PLPRESPRFR(SS) $\left(0.4 \mathrm{t} \mathrm{ha}^{-1}\right.$ of fertilizer +300 grams of insecticide +500 grams of fungicide $+2 \mathrm{t} \mathrm{ha}^{-1}$ of sugarcane seedlings +250 grams of herbicide + other inputs: irrigation). Source: Data compiled from the survey applied by the authors. 
of lack statistical significance, specifically regarding data from suppliers. In addition, this differs from the results of Carvalho et al. (2011), who found no significant yield differences between the conventional and no-till approaches, indicating lower costs per hectare for the latter.

\section{Scale of production and cost of soil preparation and planting for suppliers and sugar mills}

Soil preparation costs per hectare were higher among medium-scale suppliers (up to 799 hectares of planted area), due to the technology used for planting and soil preparation and because most opted to use their own machinery for all operations. Santos et al. (2018) also reported that suppliers incurred the highest planting and preparation costs. Small-scale suppliers (up to 399 hectares of planted area), recorded the highest planting costs. These suppliers were unable to reduce costs by expanding the scale of production and outsourced all planting activities. This corroborates the finding of Santos et al. (2018), who studied small-scale sugarcane suppliers.

The lowest cost among suppliers stratified by size was attributed to suppliers classified as medium-scale producers (up to 799 hectares of planted area). Their costs were $3.9 \%$ and $4.9 \%$ lower, respectively, than their small and intermediate scale counterparts (Table 5).

Small-scale sugarcane mills (up to 19,999 hectares of planted area) used their resources more efficiently and applied a higher percentage of sugarcane residues (vinasse and filter cake) in the reformed areas (low-yield areas replanted). This practice resulting in $23 \%$ and $18 \%$ lower costs than medium (up to 39,999 hectares of planted area), and large-scale mills (up to 800 hectares of planted area), respectively (Table 6).

\section{Economic feasibility of sugarcane suppliers and mills}

The economic viability for sugarcane suppliers and mills was evaluated by forecasting costs on purchases of machinery and equipment for soil preparation, planting, and crop treatments. This analysis was performed selecting the groups of sugarcane producers with the greatest representativeness among small, medium, and large-scale producers in both categories (suppliers and mills). Therefore, calculations were done using the data of small-scale suppliers (252 ha) and medium-scale sugar mills $(29,500$ ha) in a 10- year forecast period (two cycles).

In order to perform the analyses, cash flows were compiled based on the methodological principles suggested by Carvalho et al. (2011) that used primary data on production costs of sugarcane mills to calculate revenue. The highest costs were recorded in the first and sixth year, mostly attributed to planting costs (51 \%), followed by cutting, transshipment and transportation (CTT) operations $(35 \%)$ and $14 \%$ of soil preparation (Table 7).

Table 5 - Total crop establishment costs for sugarcane suppliers by scale of production.

\begin{tabular}{|c|c|c|c|}
\hline & Small & Medium & Large \\
\hline Soil preparation (US\$ ha-1) & 323 & 404 & 326 \\
\hline Planting* (US\$ ha-1) & 1371 & 1312 & 1285 \\
\hline $\mathrm{CTT}^{* *}$ (US\$) & 743 & 751 & 714 \\
\hline Crop management ${ }^{* * *}$ (US\$) & 437 & 437 & 437 \\
\hline Total cost (US\$ ha-1) & $2874^{a}$ & $2904^{a}$ & 2762 \\
\hline Yield (t ha-1) & 92 & 92 & 88 \\
\hline $\operatorname{Cost}\left(U S \$ t^{-1}\right)$ & 31 & 32 & 31 \\
\hline
\end{tabular}

Amounts followed by the same letter in the columns do not differ significantly between groups according to the t test $(p<0.05)$; * Planting cost included mechanization, labor and inputs costs; ${ }^{\star *} \mathrm{CTT}$ : cutting, transshipment and transportation (acronym in Portuguese); ${ }^{* * *}$ Equal cost for crop management assuming the same technology for these practices.

Table 6 - Total crop establishment costs for sugarcane mills by scale of operation.

\begin{tabular}{|c|c|c|c|}
\hline & Small & Medium & Large \\
\hline Soil preparation (US\$ ha-1) & 412 & 481 & 1191 \\
\hline Planting * (US\$ ha-1) & 1291 & 1366 & 1307 \\
\hline $\mathrm{CTT}^{\star * *}$ (US\$) & 704 & 670 & 625 \\
\hline Crop management ${ }^{* * *}$ (US\$) & 437 & 437 & 437 \\
\hline Total cost (US\$ ha $\left.{ }^{-1}\right)$ & $2844^{a}$ & $2954^{a}$ & $3561^{\mathrm{a}}$ \\
\hline Yield $\left(\mathrm{t} \mathrm{ha}^{-1}\right)$ & 87 & 82 & 77 \\
\hline Cost $\left(U S \$ t^{-1}\right)$ & 33 & 36 & 46 \\
\hline
\end{tabular}

Amounts followed by the same letter in the columns do not differ significantly between groups according to the t test $(p<0.05)$; *Planting cost included mechanization, labor and inputs costs; ${ }^{*} \mathrm{CTT}=$ cutting, transshipment and transportation (acronym in Portuguese); ${ }^{* * *}$ Equal cost for crop management assuming the same technology for these practices.

Table 7 - Gross revenue, annual costs and cash flows of small-scale sugarcane suppliers and medium-scale sugarcane mills.

\begin{tabular}{|c|c|c|c|c|c|}
\hline \multicolumn{6}{|c|}{ Small-scale Suppliers (Investment = US\$241,212) } \\
\hline YEARS & 1 and 6 & 2 and 7 & 3 and 8 & 4 and 9 & 5 and 10 \\
\hline Gross Revenue (+) & 561,918 & 513,056 & 439,762 & 390,899 & 342,037 \\
\hline Annual Cost (-) & $-678,424$ & $-336,874$ & $-304,481$ & $-282,887$ & $-261,292$ \\
\hline Net cash flow & $-116,506$ & 176,182 & 135,280 & 108,013 & 80,745 \\
\hline \multicolumn{6}{|c|}{ Medium-scale sugar mills (Investment $=$ US\$2,488.922) } \\
\hline YEARS & 1 and 6 & 2 and 7 & 3 and 8 & 4 and 9 & 5 and 10 \\
\hline Gross revenue (+) & $62,920,099$ & $51,480,081$ & $45,760,072$ & $40,040,063$ & $37,180,059$ \\
\hline Annual cost (-) & $-82,695,605$ & $-35,643,82$ & $-33,115,721$ & $-30,587,758$ & $-29,323,779$ \\
\hline Net cash flow & $-19,775,506$ & $15,836,399$ & $12,644,352$ & $9,452,305$ & $7,856,280$ \\
\hline
\end{tabular}


Table 8 - Sensitivity analysis of economic performance for smallscale sugarcane suppliers and medium-scale sugarcane mills.

\begin{tabular}{|c|c|c|c|}
\hline & Pessimistic & $\begin{array}{c}\text { Net Cash } \\
\text { Flow (NCF) } \\
\text { (US\$) } \\
\text { Realistic }\end{array}$ & Optimistic \\
\hline \multicolumn{4}{|c|}{ Small-scale Suppliers (Investment = US\$ 241,212) } \\
\hline Net cash flow & 307,482 & 394,522 & 532,975 \\
\hline Net Present Value & $-12,482$ & 46,639 & 91,965 \\
\hline Internal Rate of Return & $14 \%$ & $19 \%$ & $23 \%$ \\
\hline \multicolumn{4}{|c|}{ Medium-scale sugar mills (Investment $=$ US\$2,488,922) } \\
\hline Net cash flow & $37,278,919$ & $50,676,271$ & $63,902,993$ \\
\hline Net Present Value & $9,459,372$ & $16,570,180$ & $23,624,694$ \\
\hline Internal Rate of Return & $30 \%$ & $42 \%$ & $56 \%$ \\
\hline
\end{tabular}

Analysis of projected cash flows for small-scale sugarcane suppliers showed that sugarcane production was viable (positive NPV and IRR greater than the cost of capital) in the realistic and optimistic scenarios; however, just below the required return on capital for the pessimistic price option (Table 8). Regarding the medium-scale sugar mills, NPV and IRR values indicated that sugarcane production was viable for all price scenarios considered (Table 8).

\section{Conclusions}

Among the options considered in this study, the least costly soil preparation and sugarcane planting systems were no-till soil preparation with a fixed application rate of soil amendments and mechanized planting with a fixed application rate of fertilizers. Although the minority of sugarcane growers used these options, they are likely to be adopted because of their cost advantage; nevertheless, yield reductions and high investments required for machinery seem to hinder this action.

When considered separately, soil preparation and sugarcane planting costs per hectare were lower among sugarcane suppliers than they were for sugar mills and the lowest cost among the combined options for soil preparation and planting systems analyzed was also obtained by sugarcane suppliers. The means and actions to reduce this gap between suppliers and mills should be the objective of further research with a comprehensive survey including all categories of sugarcane producers. There was no significant difference in cost per ton of sugarcane across the different groups of suppliers; however, the rising cost per ton of sugarcane as the size of the sugar mills increased, caused by decreasing yields of cane, is a relevant problem to be studied in further research. Still, the indicators of economic viability were higher in all scenarios evaluated for medium-scale sugarcane mills than for small-scale sugarcane suppliers.

\section{Authors' Contributions}

Conceptualization: Amorim, F.R.; Patino, M.T.O. Data Acquisition: Amorim, F.R. Data Analysis: Amorim, F.R.;
Patino, M.T.O.; Santos, D.F.L. Design of methodology: Amorim, F.R.; Patino, M.T O. Writing and Editing: Amorim, F.R.; Patino, M.T.O.; Santos, D.F.L.

\section{Acknowledgments}

To the National Council for Scientific and Technological Development (CNPq) for the scholarship awarded.

\section{References}

Cardoso, F.; Watanabe, M.D.B.; Souza, A.; Chagas, M.F.; Cavalett, O.; Morais, E.R.; Nogueiras, L.A.H.; Leal, M.L.R.V.; Braunbeck, O.A.; Cortez, L.A.B.; Bonomi. A. 2019. A regional approach to determine economic, environmental and social impacts of different sugarcane production systems in Brazil. Biomass and Bioenergy 120: 9-20.

Carvalho, L.A.; Silva-Junior, C.A.; Nunes, W.A.G.A.; Meurer, I.; Souza-Júnior, W.S. 2011. Productivity and economic feasibility of sugar cane in different systems of tillage in west-central Brazil. Revista de Ciências Agrárias 34: 199-211 (in Portuguese, with abstract in English).

Demattê, J.A.M.; Demattê, J.L.I.; Alves, E.R.; Barbosa, R.N.; Morelli, J. 2014. Precision agriculture for sugarcane management: a strategy applied for brazilian conditions. Acta Scientiarum. Agronomy 36: 111-117.

Farina, E.; Zechin, M.R.; Rodrigues, A.P.; Belon, J.G.O.; Sousa, E.L.; Kutas, G.; Phillips, L.; Camargo, R.; Szwarc, A.; Zilmar, J.S. 2018. Challenging scenarios on the sugarcane sector. Agroanalysis 38: 30-36 (in Portuguese, with abstract in English).

Farinelli, J.B.M.; Santos, D.F.L.; Fernandes, C.; Fernandes, M.M.H.; Silva, M.F. 2018. Crop diversification strategy to improve economic value in Brazilian sugarcane production. Agronomy Journal 110: 1402-1411.

Manoel, A.A.S.; Moraes, M.B.C.; Santos, D.F.L.; Neves, M.F. 2018. Determinants of corporate cash holdings in times of crisis: insights from Brazilian sugarcane industry private firms. International Food and Agribusiness Management Review 21: 201-217.

Marin, F.R.; Jones, J.W. 2014. Process-based simple model for simulating sugarcane growth and production. Scientia Agricola 7: 11-16.

Moraes, E.R.; Domingues, L.A.S.; Medeiros, M.H.; Peixoto, J.V.M.; Lana, R.M.Q. 2016. Productivity and agronomic characteristics of sugarcane under different soil tillage systems. Revista de Agricultura Neotropical 3: 27-32 (in Portuguese, with abstract in English).

Neupane, P.R.; Maraseni, T.N.; Kohl, M. 2017. The sugarcane industry in Nepal: opportunities and challenges. Environmental Development 24: 86-98.

Sanches, G.M.; Paula, M.T.N.; Magalhães, P.S.; Duft, D.G.; Vtti, A.C.; Kolln, O.T.; Borges, B.M.M.; Franco, H.C.J. 2019. Precision production environments for sugarcane fields. Scientia Agricola 76: 10-17.

Santos, D.F.L.; Souza, C.A.F.; Farinelli, J.B.M.; Silva, B.L.; Horita, K. 2018. Economic analysis of sugarcane prodution under distinct technological sets. Estudo \& Debate 25: 262-283 (in Portuguese, with abstract in English). 